diate or else very difficult to obtain. A first attempt fell wide of the mark : Segre, in his great work on cubic threefolds, written about 1887, had tried to grapple with the problem; but it turned out that the varieties he considered, though rational, were not general of their type. The problem was then taken up by Prof. Gino Fano, of Turin, one of Castelnuovo's first pupils. In a struggle which has lasted some fifty years, Fano has made vital contributions to the subject, culminating last year with the news, in a letter from Switzerland, that he had succeeded in showing that the general cubic threefold is irrational. It would be an under-statement to say that geometers await with impatience the appearance of Fano's investigation.

\section{Miss P. M. Taylor}

Miss P. M. TAYLoR, who has recently been appointed woman educational officer to the Central Council for Health Education, was eqducated at Girton College, Cambridge, and Westfield College, London. Miss Taylor joined the executive committee of the Association of Women Science Teachers in 1932, and in 1935 was elected honorary general secretary, in which capacity she served until October 1944. Her new position with the Central Council is an important one which necessitated her relinquishing the onerous duties of the general secretaryship of the A.S.W.T., though she was re-elected to the Executive Committee this year. The present investigations of the Association, which have already resulted in the publication of the pamphlet "Pre-Nursing Course in Schools" (1943) and the Interim Report on Science in PostPrimary Education (1944), are in a large measure due to the initiative and exceptional powers of organization of Miss Taylor. The Association is fortunate in having her continued co-operation in the completion of this work, the results of which it is hoped to publish shortly. Miss Taylor's zeal is unabated, in spite of the calls made upon her and her capable assistants during the war years to keep in touch with the members. Their success is seen in the vigorous growth in membership and the widespread interest in progressive methods of science teaching, which factors have necessitated the appointment of a full-time secretary. In addition to her work as honorary general secretary, Miss Taylor has served on the Education Advisory Committee of the Central Council for Health Education, the Consultative Committee to the Nursing Reconstruction Committee, Royal College of Nursing, and as president of the Essex Branch of the A.W.S.T. She held the post of senior science mistress at the Southend-on-Sea High School for Girls until July 1944.

\section{Agricultural Zoology in Scotland}

Dr. D. S. MAcLAGAN, lecturer in zoology at King's College, University of Durham, has been appointed head of the Department of Zoology of the West of Scotland College of Agriculture, Glasgow, and research advisory officer in agricultural zoology for the southwest of Scotland, in succession to Prof. L. A. L. King, who has retired. Dr. MacLagan held a Ministry of Agriculture research scholarship during which he carried out work at the Parasite Laboratory of the Imperial Bureau of Entomology and at Harvard University, and later worked with a Carnegie research fellowship at the University of Edinburgh. $\mathrm{He}$ is known for his work in animal ecology and on the dynamics of animal populations.

\section{Cosmic Ray Investigations in Armenia}

THe preliminary results of the Alagez Expedition of 1944 for the study of cosmic rays have been published in the U.S.S.R. Observations have been made each year since 1942 from a camp on Mt. Alagez in Armenia at a height of about 10,000 ft. above sea-level. All instruments, supplies and camp equipment had to be carried on pack animals. As conditions are extremely favourable for the study of cosmic rays, it has now been decided to build a permanent station there, with an observation post at about $13,000 \mathrm{ft}$. It is now believed that cosmic rays contain a third element in addition to mesotrons and electrons. The particles which make up this third element have a greater ionizing effect on air than either mesotrons or electrons. The latest expedition spent three months in attempting to discover the nature of this third component, especially the mass of the particles of which it is composed. The difficulty was to separate them from the other already known components. New methods were evolved, and some new and extremely sensitive instruments built. The particles were found to have properties very similar to those of protons. The part they play is apparently more significant than was at first realized. Only preliminary data, however, have been obtained, and the material is still being studied. The expedition made several thousand observations during great cosmic ray showers for the purpose of determining the energy of the cosmic particles which cause the showers. It was found to be enormous. A special kind of shower, occurring over a very small area, but including a tremendous number of particles, was also discovered.

\section{Stone Age Implements in India}

India is rich in relics of Stone Age man, and the prehistorian there has a wide field for research. Not a great deal of new information will be gleaned from "Pre- and Proto-history of Gujarat" (H. D. Sankalia, reprinted from "The Glory that was Gürjaradesa", 1943), though the gazetteer of finds at the end of the article is useful so far as it goes. What the prehistorian asks from researchers in the field in India is definite stratigraphical data. Perhaps, therefore, the geological section of the right bank of the Sabarmati River at Pedhāmli appearing on p. 15 is the most important single item in the article. It would seem that, as throughout Madras, early Stone Age artefacts come from a gravel conglomerate which rests immediately upon laterite. The occurrence of a microlithic industry suggests that its makers were using composite tools in which several 'pigmy' flints were hafted together to form one efficient instrument. Such industries appear at various different periods when natural circumstances permit or encourage their development and may be of widely different ages; and one must enter a caveat against the wisdom of trying to correlate the microlithic finds of Gujarat with those of Europe. In India itself, Colonel Gordon, in "Indian Art and Letters" (1936), has shown that the rock-shelter paintings in the Mahadeo Hills are not very old-maybe first century B.c. to tenth century A.D. in date. There the only industries found in the rock-shelters below the paintings consist of typical Indian pigmy artefacts. Near the surface a little pottery occurs; in lower levels this is absent. The conclusion would seem to be that the pigmy industries themselves are not very old and certainly nothing to do with the European Mesolithic either culturally or in time. This is also true of the numerous 